\title{
Isolation and identification of common fungal spp. from commercial broiler feeds available in market of Sylhet District, Bangladesh
}

\author{
Islam $\mathrm{MT}^{1^{*}}$, Hossain MK ${ }^{1}$, Elahi ATMM ${ }^{1}$, Purkayastha $\mathrm{M}^{1}$, Rahman $\mathrm{MM}^{2}$ \\ ${ }^{1}$ Department of Microbiology and Immunology, ${ }^{2}$ Department of Medicine, Faculty of Veterinary and Animal \\ Science, Sylhet Agricultural University, Sylhet-3100, Bangladesh
}

[Received: December 20, Accepted: December 25, 2014]

\begin{abstract}
The present study was designed to investigate the mycological contamination of commercial broiler feeds used in poultry establishments in sylhet, Bangladesh. The feed samples of commercial broiler feed (Starter, Grower and Finisher) were collected from the different areas of Sylhet district. A total of 189 commercial broiler feed samples where 63 Starter, 63 Grower and 63 Finisher were collected from the different areas of local market in Sylhet. The selected areas were Kadamtali, Shibjong, Khadim, Kamal Bazar, Dakshin Surma, Fenchugonj. From the feed samples analyzed for the presence of fungal agents, 144 (76.2\%) were found positive for one or more fungal species. Fungal isolates were found among $36(57 \%)$ of the 63 Starter feed samples, 45 (71.4\%) of the 63 Grower feed samples and $63(100 \%)$ of the 63 Finisher feed samples. The fungal agents isolated from Broiler Starter Feeds, Aspergillus spp. 51 (70.8\%) has the highest frequency of occurrence, followed by Fuserium spp. 12 (16.7\%) and least is Rhizopus sp. 9(12.5\%). Similarly, in case of Broiler Grower Feeds, Aspergillus spp. $66(68.8 \%)$ has the highest frequency of occurrence, followed by Fuserium spp. 18 (18.7\%) and least is Rhizopus sp. 12(12.5\%). In case of Broiler Finisher Feeds, Aspergillus spp. 90 (69.8\%) has the highest rate of occurrence followed by Fuserium spp. 24 (18.6\%) and least is Rhizopus sp. 15 (11.6\%) respectively. Keywords: Commercial Broiler feed (Starter, Grower and Finisher), Isolation, Aspergillus spp., Fuserium spp., Rhizopus spp.
\end{abstract}

\section{INTRODUCTION}

The advancement of poultry industry in Bangladesh is interrupted by a number of constraints of which the major one is the outbreak of diseases causing about $30 \%$ mortality of chickens in every year ${ }^{[3]}$. The major etiological agents are the microorganisms (Bacteria, Virus, Fungus etc.), parasite and deficiency of mineral and vitamins. Poultry feed may serve as a carrier for a wide variety of microorganisms including pathogenic fungal species (The genera included Aspergillus, Fusarium, Rhizopus etc. spp.) ${ }^{[5]}$. Funguses are adapted to the low amount of available moisture and grow actively within stored seeds and grains ${ }^{[15]}$. Fungus can affect feed quality negatively of reducing dry matter and nutrients, causing musty or sour odours, causing caking of the feed and most importantly producing mycotoxins ${ }^{[15]}$. Mycotoxins are harmful substances produced by fungi in various feeds are estimated to affect as much as $25 \%$ of the world's crop each year [12]. Most of these mytocoxins belong to the three genera of fungi: Aspergillus, Penicillium and Fusarium. Due to the diversity of their toxic effects and their synergetic properties, mycotoxins are considered as risky to the consumers of contaminated feeds ${ }^{[27]}$. Talha (1999) detected Aspergillosis in $4.20 \%$, Aflatoxicosis in $0.52 \%$ in poultry in Mymensingh district of Bangladesh. In another survey conducted on breeding, commercial broiler and layer flocks of major poultry raising belts in and around Dhaka and Gazipur districts of Bangladesh and recorded Aspergillosis in $1.5 \%$ birds examined [21]. Aspergillus spp is the most common fungi found in air or litter of poultry houses [9, 14, 22, 26]. Spores are widely distributed in nature and birds of almost all species and ages may be affected where the commonest route of infection probably by inhalation ${ }^{[6]}$.Fungi grow well between $21^{\circ} \mathrm{C}$ and $32^{\circ} \mathrm{C}$ temperature and above $70 \%$ relative humidity. Bangladesh is a tropical country with a predominant hot humid environment and the environment is much favorable for the propagation of fungi on feed and feed materials. To prevent economic losses in poultry flocks isolation and identification of birds being affected by fungal infection needs to be determined. Such studies on commercial broiler feed sample in Bangladesh is not well reported. Thus, the present study is designed to investigate the mycological contamination of commercial broiler feeds used in poultry establishments in Sylhet, Bangladesh. In view of above considerations, the present study is proposed with the objectives of isolation of fungal species from Commercial broiler feed samples and identification of the common fungal species from isolates.

\section{MATERIALS AND METHODS}

The research work was conducted in the laboratory of Microbiology and Immunology, Sylhet Agricultural University, Sylhet from July to December 2013.

\section{Study area}

The feed samples of commercial broiler feed (Starter, Grower and Finisher) were collected from Kadamtali, Shibjong, Khadim, Kamal Bazar, Dakshin Surma and Fenchugonj, Sylhet.

\section{Experimental design}

The total study was performed in three (3) steps. The first step included feed sample collection, transportation and preservation. The second step of the experiment was isolation of fungal genera from commercial broiler feed sample and the third step 
was identification of common fungal spp. from pure culture.

\section{Collection of samples}

The Commercial Broiler feed samples were collected from different farms and dealers for the experimental study. A total number of 189 field samples were aseptically collected into sterile plastic bag from different spots and carried to the laboratory for the isolation and identification of common fungal Species.

\section{Isolation of fungal organisms}

Firstly,Ten-fold serial dilution of $1 \mathrm{~g}$ of feed with distilled water then $0.1 \mathrm{ml}$ of the dilution was cultured by spread plate technique into Potato dextrose agar (PDA) supplemented with chloramphenicol at $40 \mu \mathrm{g} / \mathrm{ml}$ and Gentamycin at 500 $\mu \mathrm{g} / \mathrm{ml}$ and incubated for 5 to 14 days at room temperature. Pure culture of the different colonies (based on morphology) was obtained by sub-culture of the isolates on potato dextrose agar plates and sabouraud's dextrose agar plates. The fungal isolates were identified to the genus/species level based on macroscopic and microscopic characteristics of the isolates obtained from pure cultures.

\section{Nutrient broth (NB)}

Nutrient broth was prepared by dissolving 13 gms of dehydrated nutrient broth into $1000 \mathrm{ml}$ of distilled water and was sterilized by autoclaving at $121^{\circ} \mathrm{C}$ under 15 pounds pressure per square inch for 15 minutes $(1 \mathrm{~kg} / \mathrm{cm} 2)$. Then the broth was dispensed into tubes $(10 \mathrm{ml} /$ tube $)$ and stored at $4{ }^{\circ} \mathrm{C}$ in the refrigerator until used.

\section{Phosphate buffer saline (PBS)}

For preparation of phosphate buffer saline, 8 grams of sodium chloride $(\mathrm{NaCl}), 2.89$ grams of disodium hydrogen phosphate $\left(\mathrm{Na}_{2} \mathrm{HPO}_{4} .12 \mathrm{H}_{2} \mathrm{O}\right), 0.2$ grams of potassium chloride $(\mathrm{KCl})$ and 0.2 grams of potassium hydrogen phosphate $\left(\mathrm{KH}_{2} \mathrm{PO}_{4}\right)$ were suspended in $1000 \mathrm{ml}$ of distilled. The solution was heated to dissolve completely. The solution was then sterilized by autoclaving at $121^{\circ} \mathrm{C}$ maintaining a pressure of 15 pounds per sq. inch for 15 minutes $\left(1 \mathrm{~kg} / \mathrm{cm}^{2}\right)$ and stored at $4-8^{\circ} \mathrm{C}$ until used. The $\mathrm{pH}$ of the solution was measured by a $\mathrm{pH}$ meter and maintained at 7.0-7 $.2^{[6]}$.

\section{Potato Dextrose Agar}

A total of 64 gms of media were properly mixed with $1000 \mathrm{ml}$ distilled water and boiled to dissolve the medium completely. It was sterilized using autoclaving at $15 \mathrm{lbs}$ pressure $\left(121^{\circ} \mathrm{C}\right)$ for 15 minutes $(1 \mathrm{~kg} / \mathrm{cm} 2)$ and mixed well before dispensing to start aseptically and with proper care so that any contamination be avoided.

\section{Sabouraud's Dextrose Agar}

A total of 65 gms of media were properly mixed with $1000 \mathrm{ml}$ distilled water and boiled to dissolve the medium completely. It was sterilized using autoclaving at $15 \mathrm{lbs}$ pressure $\left(121^{\circ} \mathrm{C}\right)$ for 15 minutes $\left(1 \mathrm{~kg} / \mathrm{cm}^{2}\right)$ and mixed well before dispensing to start aseptically and with proper care so that any contamination be avoided.

Culture of samples
An inoculum is prepared from the sample and streaked on the SDA media and incubated at room temperature. The different plate media were examined for the fungal growth every day until growth is found after 3 to 4 days of plating. Pure culture was prepared from this initial culture ${ }^{[18]}$.

\section{Preparation of pure culture}

In order to make a pure culture, spores from initial culture was transferred to media containing petridishes by sterilized inoculating loop for avoiding any contamination with other fungus and incubate for 3-4 days at room temperature until the fungal growth is found.

\section{Identification of fungus}

From pure culture, fungal colony was taken with the help of an inoculating needle on a fresh glass slide containing two drops of lactophenol cotton blue. The fungal colony was covered with a cover slip and the slides were examined under the microscope. The fungus was identified on the basis of its cultural and morphological characteristics ${ }^{[18]}$.

\section{RESULTS}

It was observed that ,from 189 feed samples analyzed for the presence of fungal agents, 144 $(76.2 \%)$ were found positive for one or more fungal species. Fungal isolates were found among 36 (57\%) of the 63 Starter feed samples, $45(71.4 \%)$ of the 63 Grower feed samples and $63(100 \%)$ of the 63 Finisher feed samples (Table 1).

Of the fungal agents isolated from Broiler Starter Feeds, Aspergillus spp. (70.8\%) has the highest frequency of occurrence, followed by Fuserium spp. (16.7\%) and least is Rhizopus spp (12.5\%) (Table 2). Similarly, in case of Broiler Grower Feeds, Aspergillus spp. $(68.8 \%)$ has the highest rate of occurrence, followed by Fuserium spp. (18.7\%) and least is Rhizopus spp. (12.5\%). And, in case of Broiler Finisher Feeds, the rate of occurrence is high in Aspergillus spp. (69.8\%) followed by Fuserium spp. $24(18.6 \%)$ and Rhizopus spp. (11.6\%) respectively (Table 2).

\section{DISCUSSION}

In the present study, fungal contamination was present in a high proportion of the commercial broiler feed samples $(76.2 \%)$ (Table 1) which is reported from many parts of the world $[7,16,19,10,11$, 20]. Different genera of contaminating fungi in the present study ranked according to their isolation frequency, where Aspergillus spp. (69.7\%) appeared to be the most prevalent, followed by Fuserium spp. $(18.3 \%)$ and the least is Rhizopus spp. (12.1\%). Similar results have been documented by other

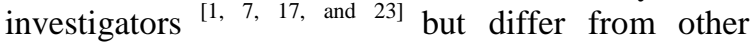
investigators [13] who stated that there is more chances of contamination by Mycotoxins. It may be stated that, Aspergillus, Fuserium and Rhizopus are the typical fungal genera inhabiting poultry feed mixtures in the study area. In fact, they are very 
Table 1: Percentage of culture positive feed sample

\begin{tabular}{llll}
\hline Sample Feed positive & Type Number & Tested Number For Fungi & Positive (\%) \\
\hline Broiler Starter & 63 & 36 & 57.00 \\
Broiler Starter & 63 & 45 & 71.40 \\
Broiler Starter & 63 & 63 & 100.00 \\
Total & 189 & 144 & 76.20
\end{tabular}

Table 2: Percentage distribution of fungal isolates in poultry feeds

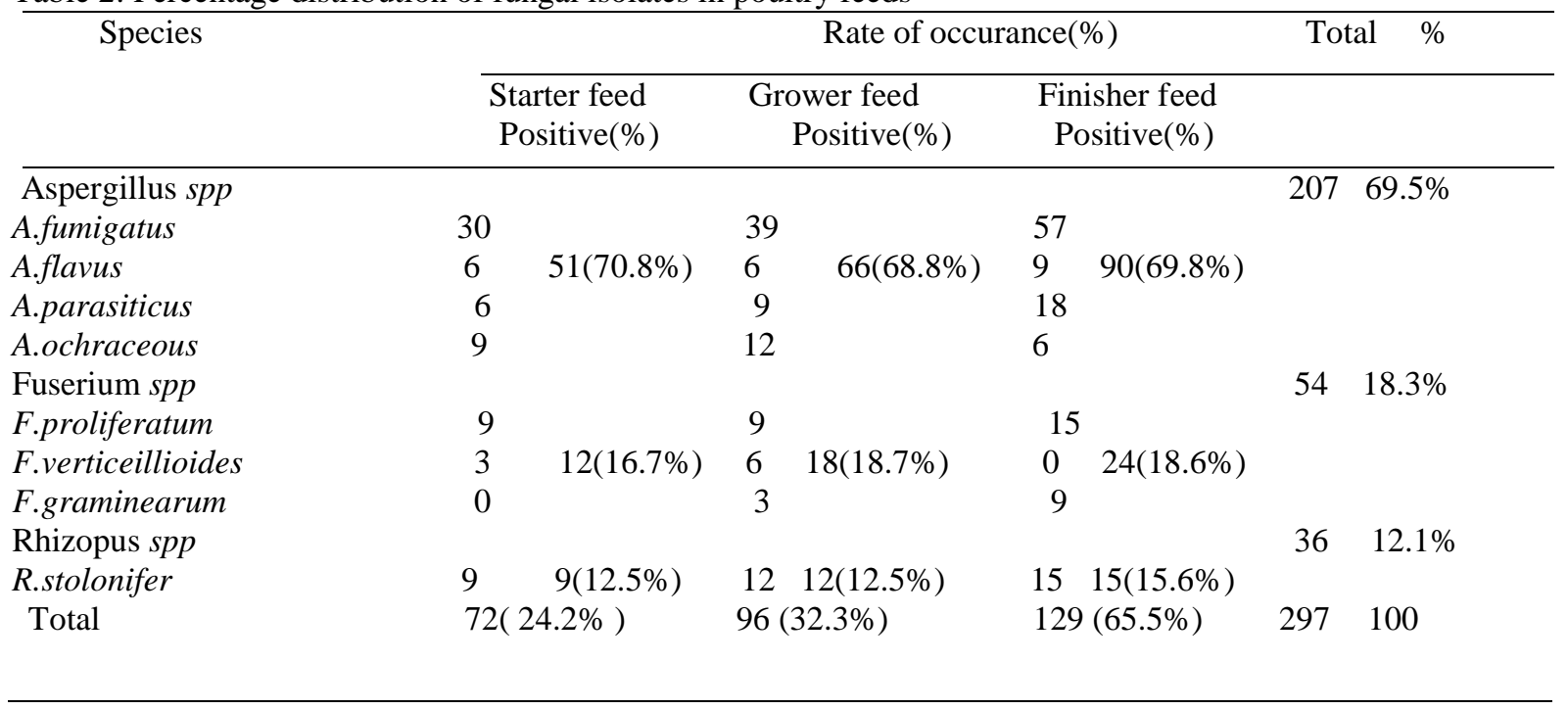

important contaminants being renowned for their ability to form a huge number of various types of toxic extrolites- mycotoxins ${ }^{[13]}$.

In the present study, high temperature and humidity might be responsible for higher frequency of isolation of Aspergillus spp. especially A. fumigatus in commercial Broiler Poultry Feeds compared with other species of Aspergillus which might be due to their high temperature tolerance character ${ }^{[4]}$. Fungal contamination frequency was higher in Broiler Finisher Feeds $(100 \%)$ as compared with Broiler starter $(57 \%)$ and Broiler Grower $(71.4 \%)$ feeds. A possible reason for low fungal contamination frequency in Broiler Starter Feeds might be inclusion of antifungal agents to prevent fungal growth. As the chicks are very sensitive to fungus oriented disease (eg. Brooder Pneumonia) and mycotoxicosis, so, antifungal inclusions are strongly used for prolonged and varied storage conditions at farms and dealer level, whereas in Broiler Grower and Broiler Finisher Feeds such inclusions might be less strongly used due to less chance of disease occurrence in case of aged birds by fungal agents.

Among the Aspergillus spp. isolated from feed samples, A. fumigatus were the predominant species followed by A. parasiticus, A. ochraceous and A. flavus. This results differ from some reports describing $A$. niger as the most predominant followed by $A$. flavus ${ }^{[20]}$ also $A$. flavus as the predominant species followed by $A$. niger aggregates $[2,19,24]$

\section{CONCLUSION}

From the study it may be concluded that, in starter feed, the company used antifungal inclusions and less used such things in grower and finisher feeds. As fungal diseases are sensitive for commercial broilers that's why different feed company use high level of fungistat during feed processing. But, this practice is harmful for public health. The use of strong antifungals in every level of feeds (Starter, Grower and Finisher) may reduces the fungal contamination of feeds when storage at dealer and farm levels; On the other hand, the feed mill manufacturing process should be maintained properly and post processing contamination should be strictly avoided. Therefore, the occurrence of fungi in commercial broiler feeds may be due to pre and post processing contamination of feed ingredients, bad manufacturing process, contamination of the feed by handlers in the farm, bad feed storage facilities in the farm among others. Due to this fact, regular microbiological and mycotoxicological analysis should be performed for maintaining quality and safety of poultry feed.

\section{REFERENCES}

1. Abdul-wahab RH(1996). Seed borne fungi in domestic bird feed in Saudi Arabia. Iraqi J. Vet. Sci. 37:223-226.

2. Accensi E, Abarca ML, Cabanes FJ (2004). Occurrence of Aspergillus spp. in mixed feeds and component raw materials and their ability 
to produce ochratoxin A. Food Microb. 21:623627.

3. Ali MI (1994). Current Status of Veterinary Biologics Production in Bangladesh and Their Quality Control. Proceedings of the BSVER symposium held on July'28, 1994 at NIPSOM auditorium, Mohakhali, Dhaka, Bangladesh.

4. Battilani P, Pietri A, Bertuzzi T, Languasco L, Giorni P, Kozakiewicz Z (2003). Occurrence of ochratoxin A producing fungi in grapes grown in Italy. J. Food Prot. 66:633-636.

5. Beuchat LR (1978). Microbial alterations of grains, legumes and oilseeds. Food Technol. 32:193-198.

6. Buxton A, Fraser G (1977). Animal Microbiology, Volume - 1, Blackwell Scientific Publications. First published, pp. 301-302.

7. Dalcero A, Magnoli C, Chiacchiera S, Palacios G M, Reynoso (1997). Mycoflora and incidence of aflatoxins $\mathrm{B}_{1}$, zearalenone and deoxinyvalenol in poultry feeds in Argentina. Mycopathologia, 137: 179-184.

8. Glender R, Oliveira J, Ribeiro M, Marcelo EF, Lilia RC, Gloria MD, Kelly MK, Ana MD, Carlos AR (2006). Mycobiota in poultry feeds and natural occurrences of aflatoxins, fumonisins and zearalenone in the Rio de Janeiro State, Brazil. Mycopathologia. 162:355-362.

9. Koctoch RC, Bhowmik KB, Katoch BS (1975). Preliminary studies on Mycoflora of poultry feed and litter. Indian Vet. J. 52: 759-762.

10. Krnjaja V, Stojanovic LJ, Cmiljanic R, Trenkovski S, Tomasevic D (2008). The presence of potentially toxigenic fungi in poultry feed. Biotechnol. Anim. Husb. 24 (5-6): 87-93.

11. Krnjaja V, Stojanovic LJ, Trenkovski S, Bijelic Z, Tomasevic D (2010). The frequency of pathogenic fungi genera in poultry feed. $J$. Food Agric. Environ. 8(3\&4): 589-591.

12. Lawlor PG and PB Lynch (2005). Mycotoxin management. African Farming and Food Processing. 46:12-13.

13. Leistner L (1984). Toxinogenic penicillia occurring in feeds and foods: A review. Food Technol. 36:404-414.

14. Lovett J, Messer JW, Read RB (1971). The Microflora of soulthera. Ohio Poultry litter. Poult. Sci. 50: 746-751.

15. Maciorowski KG, Herrera P, Jones FT, Pillai SD, Ricke SC (2006). Effects on poultry and livestock of feed contamination with bacteria and fungi. Elsevier B.V. pp. 109-136.
16. Oliveira GR, Ribeiro JM, Fraga ME, Cavaglieri LR, Direito GM, Keller KM, Dalcero AM, Rosa CA (2006). Mycobiota in poultry feeds and natural occurrence of aflatoxins, fumonisins and zearalenone in the Rio de Janeiro State, Brazil. Mycopathologia. 162: 355-362.

17. Pacin AM, Gonzalez HHL, Etcheverry M, Resnik SL, Vivas L and Espin S (2003). Fungi associated with food and feed commodities from Ecuador. Mycopathologia. 156: 87-92.

18. Rippon JW(1998). Medical Mycology. 3rd edition. Pp: 618-646.

19. Rosa CAR, Riberio JMM, Fraga MJ, Gatti M, Cavaglieri LR, Magnoli CE, Dalcero AM, Lopes CWG (2006). Mycoflora of poultry feed and ochratoxin- producing ability of isolated Aspergillus and Penicillium species. Veterinary Microbiology, 113: 89-96.

20. Saleemi MK, Khan MZ, Ahrar K, Javed I (2010). Mycoflora of poultry feeds and mycotoxins producing protential of Aspergillus species. Pak. J. Bot. 42 (1):427-434.

21. Saleque MA, Rahman MH, Hossain MI (2003). Seasonal variation in the prevalence of poultry diseases in Bangladesh. 9th BSVER annual Scientific Conference held at BAU, Mymensingh on 6 - 7 January, 2003. BSVER publication 24:23-24.

22. Scurter EA, Deterson CF, Parkinson JF, Dixon JF and Stroh RC (1981). The air borne microflora of poultry houses. Poult. Sci. 60: 569-574.

23. Shareef AM (2010). Molds and Mycotoxins in poultry feeds from Farms of potential Mycotoxicosis. Iraqi J. Vet. Sci. 24 (1):17-25.

24. Somashekar D, Rati ER, Anad S, Chandrashekar A (2004). Isolation, enumeration and PCR characterization of Aflatoxigenic fungi from food and feed samples in India. Food Microb. 21:809-813.

25. Talha AFSM (1999). Pathology of Poultry disease occurring in Mymensingh. MS thesis, Department of Pathology, Faculty of Veterinary Science, Bangladesh Agricultural University, Mymensingh.

26. Thi SD, Dick JW, Holteman KA, Labosky P (1978). Mould spore population in bask residues used as broiler litter. Poult. Sci. 57: 870-874.

27. Yiannikouris A, Jonany J (2002). Mycotoxins in feeds and their fate in animals: a review. Anim. Res.51: 81- 99. 